\title{
The effects of Self- efficacy and Motivational Orientations on Academic Achievement of Freshman Science Students
}

\author{
Amare Sahile
}

Department of Psychology, Bahir Dar University, Bahir Dar, Ethiopia \begin{abstract}
The purpose of this study was to investigate whether self-efficacy, intrinsic, extrinsic and amotivation forms of orientation affect student achievement. Hundred and eighty participants (99 males and 81females) were participated in the study. Data through questionnaire, students' grades in four introductory science courses and College English collected at the end of the semester. Regression, t-test and correlation employed for analyses. Regression results demonstrated that self efficacy, intrinsic (i.e. IM-to know and IM-task accomplishment) and extrinsic (i.e. identified regulation) forms of motivational orientations had statistically significant direct effects on academic achievement. Amotivation had negative significant direct effect on achievement. However, i.e external and introjected regulations and. IM-to experience stimulation had no effects on achievement. The t-test revealed that male students scored higher mean scores in perceived competence, identified regulation, IM-to know and performance, but there was no gender difference on the other motivational orientations. Correlational analysis indicated that except IM- to experience stimulation, external and introjected regulations, all other were correlated with academic achievement, amotivation being negatively and significantly related to performance. Finally, it was concluded that students who had external and introjected regulations and intrinsic motivational style and IMto experience stimulation and amotivation demonstrate lower level of academic achievement. It can be concluded that students' judgments of their capability in academic tasks and their autonomous motivational orientations lead to enhanced learning out comes. Therefore, science instructors and program managers need to devise interventions to uplift and capacitate students' capability and internalization of learning.
\end{abstract} Article Information

Copyright@2014 STAR Journal. All Rights Reserved.

Article History:

Received : 12-06-2014

Revised : 27-09-2014

Accepted : 28-09-2014

Keywords:

Self efficacy

Motivational orientations

Internalization

Science achievement

*Corresponding Author:

Amare Sahile

E-mail:

amsalomi1979@yahoo.com

\section{INTRODUCTION}

A large body of research has shown that motivational orientations are related to various out comes such as curiosity, persistence, learning and performance. However, much research specifically in education concerned with intrinsic motivation. This type motivation has generally focused on individuals' interest as an antecedent of school related outcomes and found to be pertinent for the field of education, (Bandura, 1977; Shunk, 1989, 1991; task motivation, Nicholas, 1984; goal orientation, Shraw et al., 1995).

According to Deci and Ryan, (2000), Vallerand and Bissonettee, (1992) a complete understanding of human behavior in education must go beyond the study of intrinsic motivation alone, and include a profound analysis of motivational forces in operation. They ascertained the concept of the three basic psychological needs that are assumed to be inherent and universal in human life. According to these writers the needs for competence, relatedness and autonomy must be satisfied for people to develop and function in a healthy or optimal ways

With regard to behavioral regulation, there is the concept of intention that focused on factors that promote versus to promote students understanding of outcome instrumentalities and engaging in efficacious states to attain those outcomes (Shunck, 1991).

With respect to controlled types of intentional regulatory processes of motivated actions in education (Deci and Ryan, 1991; Deci et al., 1991; Vallerand and Bissonnettee, 1992; Vallerand et al., 1992, 1993; Vallerand, Fortier and Guay, 1997; Gronlick and Ryan, 1987; pellitier et al., 1995; Blaise et al., 1990) claimed that intrinsic and extrinsic motivational orientations in education influence learning and subsequent achievement out of interest, internalizing values and regulatory processes; which are manifestations of high quality learning and conceptual understanding. Based on the conception of self motivated regulatory styles Deci and Ryan (1991) posited that academic behavior can be intrinsically, extrinsically motivated or amotivated.

Intrinsically motivated behaviors are actions students undertake out of interest (Deci and Ryan, 1991). Individuals engage in activities of their choosing in order to experience feelings of personal control. Activities that allow the experience of such feelings become intrinsically 


\section{Amare Sahile}

motivating and be engaged in repeatedly in the absence of apparent contingencies. Intrinsically motivated behaviors represent the prototype of autonomous activity; they emanate from the self and fully endorsed (Vallerand and Bissinotte, 1992).

Based on intrinsic motivation literature so far (Vallerand et al., 1992, 1993) have postulated that intrinsic motivation could differentiate into three specific motives that have been studied on an independent basis. They are identified as intrinsic motivation to know, intrinsic motivation toward accomplishments and intrinsic motivation to experience stimulation.

Intrinsic motivation to know is in action for the fact of performing an activity for the pleasure and satisfaction that one experiences while learning, exploring or trying to understand something new (Vallerand et al., 1992; Peltier et al., 1995). Intrinsic motivation to know can be related to exploration, curiosity, learning goals, intrinsic intellectuality to learn, the epistemic need to know and understand and that of the search for meaning. Schraw et al. (1995) findings revealed that highly motivated students invest more time and effort in mastering course material for they are motivated to improve their knowledge. Students may perceive a variety of reasons for trying to succeed academically; a student may hold efficacies beliefs that academic success may represent the opportunity to learn new and interesting information (Timothy et al., 1995).

Intrinsic motivation toward accomplishments in order when a student engaging in an activity for the satisfaction experienced when one attempts to accomplish or to create tasks (Pelletier et al., 1995; Vallerand et al., 1993). Individuals interact with the environment in order to feel competent and to create unique accomplishments. Individuals focus on the process of achieving rather than on the outcome (Vallerand et al., 1992). Trying to master or accomplish certain difficult academic activities in order to experience personal satisfaction or students who extend their work beyond the requirements of a given task in order to surpass themselves represent intrinsic motivation toward accomplishments (Vallerand, Fortier and Guay, 1997).

Intrinsic motivation to experience stimulation occurs when someone engages in an activity in order to experience stimulating sensations such as sensory pleasure, aesthetic experiences as well as fun and excitement derived from one's engagement in the activity (Vallerand et al., 1992, 1993, Pelletier et al., 1995). Students who attend classes in order to experience the excitement of stimulating class discussion, or who read a book for the intense feelings of cognitive pleasure derived from passionate and exciting passages represent examples of an experience of stimulation in education (Vallerand and Bissonnette, 1992).

Contrary to intrinsic motivation, extrinsic motivation pertains to a wide variety of behaviors where the goals extend beyond those inherent in the activity itself. They are behaviors engaged in as a means to an end and not for their own sake (Deci and Ryan, 1991, Deci et al., 1991). Extrinsic motivation was thought as behavior performed in the absence of autonomy and prompted by external contingencies. The types of extrinsic regulation viewed in terms of an externally motivated activity
Sci. Technol. Arts Res. J., July-Sep 2014, 3(3): 176-184

internalized, ordered from lower to higher levels are external regulation, introjected regulation and identified regulation.

External regulation is behavior for which the locus of initiation is external to the person. A student who does an assignment for teacher's praise or to avoid teacher's criticism is externally regulated. The behavior is performed because of an external contingency and this contingency is considered as the loci of initiation and regulation (Deci et al., 1991). External regulation may also be fueled by a desire for rewards. For instance, students may work hard at school in order to receive a prize promised by their parents or to have prestigious future life through learning.

Intojected regulation is operative when the students begin to internalize the reasons for his or her action. However, this form of internalization, while internal to the person, is not true choice since it is limited to the internalization of past external contingencies Introjection (internal controls) refer to the process whereby an external demand becomes an internal representation which the person uses to approve or disapprove of his or her actions (Fortier, Vallerand and Guay, 1995). Thus, the individual might say "I study the night before exams because I feel guilty when I don't or that is what good students supposed to do". Beliefs and controls are now imposed by the individual and not by others and experience as pressure and tension toward specific aims. These individuals seek to prove their efficacy and use conceited statements. Have a desire to do better than others and demonstrate their competence publicly, but have little desire to improve their understanding a topic under discussion.

Identified regulation occurs when the behavior becomes valued and judged important for the student and perceived as chosen by the student then the internalization of extrinsic motives becomes regulated through identification (Vallerand et al., 1992, 1993; Pelletier et al., 1995). Identification allows the person to feel a sense of choice about behaving. Students might go to school because they feel that this is the path they have chosen to follow or to have access to the career they have selected. It is a form of extrinsic motivation based more on choice. For instance, a student who willingly does extra work in physics because the student believes it is important for continuing to succeed at physics. The motivation is extrinsic because the activity is performed primarily because of its usefulness or instrumentality for the goal of improving physics achievement and succeeding in future endeavors, rather than because it is interesting. In this case the behavior is relatively autonomous because the student does it willingly, for personal reasons, rather than external pressure.

Apart from intrinsic and extrinsic motivation, the third type of motivational construct is important to consider in order to fully understanding human behavior. Individuals are amotivated when they do not perceive contingencies between outcomes and their own actions they are neither intrinsically nor extrinsically motivated (Deci et al., 1991). It is said to be a relative absence of intentional action. Amotivated students engage in the activity without any sense of purpose and do not see any relationship between their actions and the consequences of such behavior (Vallerand, Fortier and Guay 1997). They also 


\section{Amare Sahile}

feel undeceived, and start asking themselves why in the world they go to school; eventually they may stop participating in academic activities. When students are in such a state, they no longer identify any good reasons for why they continue to learn.

Motivational styles are motivational orientations of the students to behave in a predisposed ways; thus to some extent that situational variables can lead students to engage in a task with a specific orientation such as intrinsic orientation (Vallerand and Bissonette 1992). These concepts have been treated as individual difference variables, assessing the degree to which each student expresses each type of regulatory styles.

With regard to the relationship between the different motivational styles with educational outcomes findings demonstrated that the most negative association were obtained with amotivation, while the most positive correlation were found with intrinsic motivation and with identification variables. External and introjected regulation and were said to relate either negatively or not to educational outcomes.

A research conducted on interpersonal relationships (Blaise et al., 1990) demonstrated that intrinsic motivation integration identification were found to correlate negatively with amotivation and external regulation, but no relationships were found with intojected regulation. The correlation between introjection, amotivaion and external regulation were positive and significant.

Similarly, a study conducted on college students (Vallerand and Bissonette, 1992) reported that amotivation had negative significant correlation with intrinsic motivation, integration and identification, but it was related insignificantly with introjection and significantly with external regulation. On the other hand, non-significant relationship was observed between external regulation and intrinsic motivation, integration and identification, but positive association with introjected regulation. Amotivation was found to be a very important predictor of achievement, being negatively related to performance and represent a strong antecedent of negative (Vallerand and Bissonette, 1992)

\section{Self-efficacy, Motivational Styles and Academic Achievement}

With respect to motivational antecedents (determinants) the concept of self efficacy has been found to be central to motivation in education display the judgment students hold about their capability in academic domain, being self-efficacious, (Shunk, 1991) The feelings of self-efficacy with respect to activity facilitates students' and provides them with a sense of need satisfaction from engaging in an activity at which they feel effective. a sense of self-efficacy in one's academic activity is the belief that learning is no one else's responsibility but one's own. Success enhances students' feelings of self-efficacy.

Research findings (Vallerand et al., 1993) revealed that students' self-efficacy associates positively and strongly with the three forms of intrinsic motivation and identification. On the other hand it was correlated negatively with amotivation, relationship consisting the introjection and external regulations were found to be negative and no relationship, respectively.
Sci. Technol. Arts Res. J., July-Sep 2014, 3(3): 176-184

Vallerand, Fortier and Guay, (1997) indicated that persistence students shown higher levels of perceived self-efficacy in school activities than drop out students. With respect to self efficacy local studies conducted on high school students (Yalew, 1997 and Amare, 2001) indicated its relation and predicting ability of students' achievement.

\section{Gender Differences in Self- efficacy, Motivational Styles and Academic Achievement}

Studies revealed that gender and motivation are significant and independent contributors to behavioral persistence thus female persist more than male in part because their more motivational profile and because of some unknown psychological characteristic associated with their gender (Vallerand and Bissonettee, 1992). Male students scored higher in their self efficacy and performance than female students. Results indicated that no sex differences were observed on academic self efficacy and motivation, but males found to exceed females in their performance. (Yalew, 1997).

With regard to gender differences on motivation styles (Vallerand et al., 1992,) reported that female students scored higher means than males on the three IM subscales as well as on the identification and introjected subscales, however, no sex differences were found on external regulation and amotivation. A study conducted on college students (Vallerand and Bissonnettee, 1992) findings revealed that female students reported being more intrinsically motivated, integrated and identified where as males were externally regulated and amotivated toward academic activities, but no sex difference on introjection.

A research conducted on persistent $V s$ dropout high school student (Vallerand Fortier and Guay, 1997) demonstrated that female students reported higher levels of the three intrinsic motivation (to know to accomplish and to experience stimulation) and higher levels of identification and introjection. On the other hand, males reported higher levels of amotivation. However, no sex difference was found on external regulation. Amotivation was found to be a very important predictor of behavior, being negatively related to academic achievement and represent a strong antecedent of negative quencequence (Vallerand and Bissoneette, 1992).

Vallerand Fortier and Guay (1997) have indicated that one's perception of self efficacy intrinsic, extrinsic and amotivation orientations are sufficiently powerful to predict behavior in an important real life domain, namely education. According to this contention, individuals need to feel efficacious at activities or tasks over which they assume personal control. Academic activities provide participants with feelings of sense of self-efficacy. It is believed that higher levels of learning represent students to be self efficacies and motivated on the part of the learners to successfully complete a program they are engaged in. Apparently, when learners are selfefficacious and autonomously internalize the value of learning and achievement, they are more fully involved in academic activity and display better academic achievement.

First year natural science students assigned in the college of science, Bahir Dar University directly by Ministry of Education. The Ministry of Education made a 


\section{Amare Sahile}

paradigm shift in professional mix in turning over and providing training to students at university level since 2008. Apart from specifying the professional mix of graduates from the public universities the policy document seems to envisage the establishment of two universities and restructuring of an existing university with exclusive mission of provision of technology courses. The document justifies its initiation inter-alia by the following points. Ethiopia is going to transform its agricultural sector to industrialization. There are experiences that there cannot be sustainable development of industrialization or modern sector without a sufficient expertise density in science and technology. Ethiopia has suffered from brain drain to which it has not taken effective administrative measures and the brain drain would affect it in the very professions it would require most for the country's development to science and technology as a development strategy of the country (MoE, 2008). Based on this policy guideline the Ministry of Education adopted 70 and 30 (i.e from the total student population $70 \%$ are assigned to science and technology streams and the rest $30 \%$ are to social science steams). In view of the guideline it seems worth investigating to what extent students are really capable and in what way they internalize their persistence and achievement in science courses. Conducting this type of research, therefore, helps to see students' evaluation of their capability and their motivational orientations toward educational enterprise in a field setting and provides an important insight how these motivational styles affect students' learning and suggests a possible measures to be taken by concerned bodies in order to up lift students' interest particularly at higher level of academic arena. Academic achievement as a function of self-efficacy and motivational orientations is not extensively researched area in Ethiopian context. Therefore, examining the problem in the university context seems timely and important. This study might have both theoretical and practical contributions, which have direct implications to science stream students on their perceptions of capability and the motivational orientations they display to achieve on science courses at university level. Regarding the theoretical implications, the study could provide up-to-date information about the magnitude of students' academic achievement and the extent of the independent variables in predicting the academic achievement of science at university level. As a result, the instructors, university management and the university community at large could be aware of the factors that influence academic achievement of students in general and science students in particular. Regarding the practical implications, the findings of the study might help the decision makers of the university to design and implement strategies to improve students' academic performance on the one hand and improve the efficiency of university education on the other.

This study, therefore, is concerned in an attempt to examine the following basic research questions.

1. Is there significant relationship between self efficacy, intrinsic, extrinsic amotivation styles and academic performance? Which variables significantly corelated to males and female?

2. Do Academic self efficacy, intrinsic, extrinsic and amotivation styles predict strongly and significantly students performance? If so which variable will have more prediction power? What is the contribution of each variable on the variance of academic achievement?
Sci. Technol. Arts Res. J., July-Sep 2014, 3(3): 176-184

3. Are there significant gender differences in self efficacy, intrinsic, extrinsic, amotivation styles and academic achievement?

The major purpose of this study is to focus on important and unexplored research questions, which have direct implications to science stream students on their academic self-efficacy and the motivational orientations they display to achieve on science courses. More specifically the purposes of this study were

1. To examine the relationships between self-efficacy, intrinsic, extrinsic, amotivation orientations to students' academic achievement. Which variables correlate to males and females independently?

2. To investigate whether self-efficacy intrinsic, extrinsic and amotivation styles significantly predict academic achievement and thereby indicate which of the variable has more effect on the contributions of academic achievement variance.

3. To compare mean score difference between male and female students on self-efficacy, intrinsic, extrinsic, amotivation orientations and academic achievement.

The study delimited to students of science faculty of Bahir Dar University. Students of Science faculty selected considering the existing shift of area of emphasis by government in the university education to produce more science oriented graduates (70: 30) compared to other fields of academic study. Students are required to demonstrate capability and skills and this also needs highly motivated behavior to achieve better on the courses they are registered for. This study was also delimited particularly to see effects of self efficacy, intrinsic, extrinsic, and amotivation orientations on the performance of science stream students.

\section{METHODS AND MATERIALS \\ Participants}

The participants of this study were freshman natural science students of Bahir Dar University science faculty. From the total of 457 students population 180 randomly selected participated from four sections were involved in this study. Of these, 99 were males and 81 females.

\section{Instruments}

Self-Efficacy: The scale was consisted of 10 items and adapted from available literature. The instrument was designed to assess students' perception of students judgments about their ability and control over their academic work required by their learning. The students were asked to rate their degree of agreement on a 4 point scale and scores ranged from strongly disagree (1) when the items worded negatively and strongly agree (5) when the items phrased positively. The internal consistency reliability as measured by Chronbch alpha for the total items was 0.73 .

Academic Motivation Scale: The scale was adapted from Vallerand et al. (1992-93) Academic Motivation Scale (AMS HS-28) that was developed to measure students' stable motivational orientations toward education. In the present study, the scale was designed to assess students' perceived reasons "why" do they learn in the university. The reasons are scored on a 5-point scale, ranging from not at all corresponds (1) to correspond exactly (5). The scale contained a total of 28 items, 4 items measure the three intrinsic motivation styles 


\section{Amare Sahile}

namely: intrinsic motivation to know (e.g., "For the pleasure that I experience in broadening my knowledge about subjects which appeal to me"; 4 items, Chronbach alpha=0.76). Intrinsic motivation toward accomplishments (e.g.," For the satisfaction I feel when I am in the process of academic activities"; 4 items, chronbach alpha $=0.70$ ). Intrinsic motivation to experience stimulation (e.g., For the high feeling that I experience while reading about various interesting subjects"; 4 items, Chronbach alpha 0.74)

Three extrinsic motivation styles namely, identified regulation (I believe that my university education will improve my competence as a worker"; 4 items, Chronbach alpha $=0.77$ ). Introjected regulation (e.g. To prove to myself that I am capable of completing my university degree"; 4 items, Chronbach alpha $=0.70$ ). External regulation (e.g., "I need a university degree in order to find a high paying job later on"; 4 items, Chronbach alpha $=0.81$ ) and,

Amotivation (e.g., I don't know; I can't understand what I am doing in the university"; 4 items, Chronbach alpha = $0.74)$.

Academic Achievement: -Students' first semester final grades in five courses, namely: Mechanics and heat, General Chemistry, Preliminary Mathematics, General Biology and College English were collected from the registrar office. Letter grades were converted into their standard equivalents to determine students' academic achievement. Thus, $A=4, B=3, C=2, D=1$ and $F=0$.
Sci. Technol. Arts Res. J., July-Sep 2014, 3(3): 176-184

Before administration of the questionnaire, consent retained from students to participate in the study. Confidentiality of the responses of the participants communicated to keep responses strictly at all times. The investigator explained the purpose of the questionnaire to the participants and administered to the participants during a regular schedule class time after obtaining instructors permission in their respective departments. The investigator gave instruction and illustration how to fill in the questionnaire. No time restriction made to participants to complete and return the questionnaire. After participants completed filling in the questionnaire the investigator collected the questionnaire and thanked for their participation.

\section{Data Analysis}

- Pearson product moment coefficient of correlation calculated to examine whether there exists relationships between the independent and dependent variables.

- Regression analysis was used to see whether the scores of independent variables predict strongly and significantly students' performance.

- Independent t-test used to compare the mean score of male and female students on the variables treated.

\section{RESULTS}

The first purpose of this study was to examine whether there exist interrelationships between perceived competence, intrinsic extrinsic, amotivation and academic performance. To do this, correlation coefficient statistic was performed and the results presented in Table 1.

Table 1: Means, standard deviations and interrelationships between the variables in the study for the total group $(\mathrm{N}=180)$ [sex codes were $0=$ female, $1=$ male]

\begin{tabular}{|c|c|c|c|c|c|c|c|c|c|c|}
\hline Variables & $\mathbf{M}$ & GEN & PCO & AMO & EX-R & IN-R & ID-R & IM-K & IM-A & IM-S \\
\hline GEN & & & & & & & & & & \\
\hline SelEff & $\overline{31.12}$ & $\overline{0.190 *}$ & 1.00 & & & & & & & \\
\hline $\mathrm{AMO}$ & 6.19 & $-0.047(\mathrm{~ns})$ & $-0254^{* * *}$ & 1.00 & & & & & & \\
\hline EX-R & 14.68 & 0.123 & $0.007(\mathrm{~ns})$ & $0.099(\mathrm{~ns})$ & 1.00 & & & & & \\
\hline IN-R & 12.58 & -0.027 & $0.042(\mathrm{~ns})$ & $0.185^{\star}$ & $0.440^{* * *}$ & 1.00 & & & & \\
\hline ID-R & 15.72 & $0.152^{*}$ & $0.342^{* \star *}$ & $-0.056(\mathrm{~ns})$ & $0.463^{\star \star *}$ & $0.376^{* * *}$ & 1.00 & & & \\
\hline IM-K & 15.79 & $0.241^{* * *}$ & $0.360^{* * *}$ & $-0.072(\mathrm{~ns})$ & $0.034(\mathrm{~ns})$ & $0.363^{* * *}$ & $0.431^{\star \star *}$ & 1.00 & & \\
\hline IM-A & 13.22 & $0.116(\mathrm{~ns})$ & $0.205^{\star \star}$ & $0.083(\mathrm{~ns})$ & $0.130(\mathrm{~ns})$ & $0.539^{* * *}$ & $0.394^{\star \star \star}$ & $0.623^{\star \star *}$ & 1.00 & \\
\hline IM-S & 11.86 & $0.034(\mathrm{~ns})$ & $0.093(\mathrm{~ns})$ & $0.187^{\star}$ & $0.299^{* * *}$ & $0.571^{* * *}$ & $0.440^{* * *}$ & $0.552^{* \star *}$ & $0.584^{* * *}$ & 1.00 \\
\hline AcaAchl & 11.06 & $0.440^{* * *}$ & $0.352^{* * *}$ & $-0.268^{* * *}$ & $0113(\mathrm{~ns})$ & 0.033 (ns) & $0.313^{* * *}$ & $0.237^{* * *}$ & $0.204^{* *}$ & $0.092(\mathrm{~ns})$ \\
\hline
\end{tabular}

IM-S= Intrinsic Motivation to experience stimulation; NT-R= Introjected Regulation; GEN =Gender SelEff=self-efficacy; M- K= Intrinsic Motivation to know; IM-A=intrinsic Motivation toward accomplishment; ID-R=identified regulation; $A M O=A m o t i v a t i o n ; ~ E X-R=E x t e r n a l$ Regulation and AcaAchi = Academic achievement

As indicated in Table1. External regulation and introjected regulation and IM- to experience stimulation were not correlated with performance. On the other hand, gender, perceived competence, identified regulation, IM to know and IM toward accomplishments significantly correlated with performance. amotivation had significant negative association with academic achievement.

Self efficacy was found to correlate with Identification, IM-to know and toward accomplishment, but not correlated with IM-to experience stimulation, introjected and external regulations. The correlation between selfefficacy and amotivation was significant and negative $(r=$ -0.254). Similarly, gender was found to correlate with perceived competence and the two forms of selfdetermined motivation, identified regulation and IM to know $(r=0.190, P<0.05 ; r=152, P<0.05$ and $r=0.241$, $P<0.001)$ respectively. A negative insignificant relationship was observed with amotivation and introjection. On the other hand, insignificant correlation was found between IM- toward accomplishments, IM-to experience stimulation and external regulation.

Likewise, the three IM showed the highest positive correlations among themselves $(r=0.623, P<0.05, \quad r=$ $0.552, P<0.05$ and $r=0.584, P<0.05)$. These correlations were very similar to those obtained by Vallerand et al. (1993). The correlations obtained in this study show that the three sub scales assess a similar but not identical construct. Similarly, correlations between adjacent subscales displayed higher relationship (e.g., IM to know and Identification, $r=0.431$ ) than subscales further apart (e.g., IM to know and Introjection, $r=0.363$ ). On the other hand, correlation at the opposite ends (e.g., Amotivation and IM to know, $r=-0.072$ ) showed negative insignificant relation between intermediate variables (Introjection and Amotivation, $\quad r=0.185)$, which displayed positive correlations. 


\section{Amare Sahile}

Of the three IM styles, IM to experience stimulation was found to correlate with the two extrinsic motivational styles, i.e. Introjection $(r=0.571, P<0.05)$ and external regulation $(r=0.299, P<0.05)$ and with self-determined type of extrinsic motivation, Identification $(r=0.376, P<0.05)$
Sci. Technol. Arts Res. J., July-Sep 2014, 3(3): 176-184

and the relationship with the amotivation variable was positive and significant $(r=0.187, P<0.05)$. But the relationship between identification and amotivation was negative and non- significant (- 0.056).

Table 2: Correlational matrix between the variables for males $(n=99)$ and females $(n=81)$ in the study. Correlation below the diagonal for males and above the diagonal for females

\begin{tabular}{|c|c|c|c|c|c|c|c|c|c|}
\hline Variables & SelEff & AMO & EX-R & IN-R & ID-R & IM-K & IM-A & IM-S & AcaAchiER \\
\hline SelEff & & $-0.304^{\star *}$ & -0.041 & -0.051 (ns) & $0.317^{* *}$ & $0.258^{*}$ & $0.218^{*}$ & $-0.064(\mathrm{~ns})$ & $0.349^{* *}$ \\
\hline $\mathrm{PCO}$ & $-\overline{0.184(n s)}$ & & $0.069(\mathrm{~ns})$ & $0.117(\mathrm{~ns})$ & $-0.097(\mathrm{~ns})$ & $0.253^{*}$ & $0.015(\mathrm{~ns})$ & 0.220 * & $-0.289^{* *}$ \\
\hline AMO & $-0.021(\mathrm{~ns})$ & $0.144(\mathrm{~ns})$ & & $0.403^{* * *}$ & $0.429^{\star * *}$ & $-0.075(\mathrm{~ns})$ & $-0.005(\mathrm{~ns})$ & $0.270^{*}$ & $0.120(\mathrm{~ns})$ \\
\hline EX-R & $0.156(\mathrm{~ns})$ & $0.246^{*}$ & $\overline{0.48} 7^{* * *}$ & & $0.346^{* *}$ & $0.016(\mathrm{~ns})$ & $0.502^{\star * *}$ & $0.587^{* * \star}$ & 0.041 (ns) \\
\hline IN-R & $0.334^{* * *}$ & $-0.001(\mathrm{~ns})$ & $0.477^{* * *}$ & $\overline{0.420}$ *** & & $0.509^{* * *}$ & $0.340^{\star *}$ & $0.339^{* *}$ & $0.375^{* * *}$ \\
\hline ID-R & $0.430^{* * *}$ & $-0.050(n s)$ & $-0.007(\mathrm{~ns})$ & $0.263^{\star *}$ & $0.394^{* * *}$ & $0.428^{* * *}$ & $0.642^{\star \star \star}$ & $0.576^{\star * *}$ & $0.103(\mathrm{~ns})$ \\
\hline IM-K & 0.163 & 0.154 & 0.221 * & $0.580^{* * *}$ & $0.423^{\star \star \star}$ & & & $0.515^{\star * *}$ & $0.232^{*}$ \\
\hline IM-A & $0.239^{*}$ & 0.166 & $0.322^{\star \star *}$ & $0.565^{\star * *}$ & $0.524^{\star * *}$ & $\overline{0.603}^{\star \star \star}$ & $\overline{0.630}^{\star * *}$ & & 0.035 (ns) \\
\hline IM-S & $0.237^{*}$ & $-0.262^{\star *}$ & $0.001(\mathrm{~ns})$ & 0.061 (ns) & $0.161(\mathrm{~ns})$ & $0.559^{* * *}$ & $0.115(\mathrm{~ns})$ & 0.139 (ns) & \\
\hline PER & & & & & & $0.214^{*}$ & & & \\
\hline
\end{tabular}

Table 2 shows intercorrelations of the variables for males and females. Except, the correlations between SelEff and AcaAchi $(r=0.237, \quad P<0.05), \quad A M O$ and AcaAchiv ( $r=-0.262, P<0.01)$, and IM-K and AcaAchi $(r=0.214, P<0.05)$ for males were significant, but all others were not significant $(p=0.05)$. On the other hand, except the correlation between EX-R and AcaAchi ( $r=0.120$, $P<0.05)$ and INT-R and AcaAchi $(r=0.41, P<0.05)$, IM-K and AcaAchi $(0.103, P<0.05)$ and IM-S and AcaAchi ( $r$ $=0.035, \quad P<0.05$ ) for females were not significant, all others were significant $(P<0.05)$.

The most important motivational orientations that were related to Academic achievement for male students were, in decreasing order: IM-to know, identified regulation, IMto experience stimulation, IM-toward accomplishments, introjected regulation and external regulation. On the other hand, identified regulation, IM-toward accomplishments, external regulations, IM-to know, introjected regulation and $\mathrm{IM}$-to experience stimulation were in decreasing order for females.

The second purpose of this study was to investigate whether self efficacy, intrinsic, extrinsic and amotivation variables predict significantly academic achievement and to see the contribution of each variable on the variance of the dependent variable, academic achievement. To do this regression analysis was conducted and the results portrayed in Table 4 below.

Table 3: Regression statistics of the independent variables on academic achievement

\begin{tabular}{ccccc}
\hline Variables & $\mathbf{R}^{2}$ & Coefficients & t-statistic & $\boldsymbol{P}$-value \\
\hline PCO & & 0.208 & 4.245 & $<0.05$ \\
AMO & 0.323 & -0.347 & -3.813 & $<0.001$ \\
EX-R & & 0.059 & 0.881 & $>0.05$ \\
IN-R & & 0.043 & 0.662 & $>0.05$ \\
ID-R & & 0.319 & 3.843 & $<0.001$ \\
IM-K & & 0.149 & -2.014 & $<0.05$ \\
IM-A & & 0.166 & 2.306 & $<0.05$ \\
IM-S & 0.084 & 1.151 & $>0.05$ \\
\hline
\end{tabular}

As indicated in table 4 the direct effects of the variables were determined using path coefficients. The effects on performance of perceived competence ( $\beta$ $=0.278, \mathrm{t}=4.245, P<0.05)$, identified regulation $(\beta=.252, \mathrm{t}=$ 3.843, $P<0.05)$ IM to know $(\beta=0.139, \mathrm{t}=2.014, P>0.05)$, IM to accomplish tasks $(\beta=0.155, \mathrm{t}=2.306, P<0.05)$ were all positive and significant. But the effect of amotivation on performance was negative and significant $(\beta=-0.248, \mathrm{t}=$ -3.691, $P<0.001)$. On the other hand, the effects on performance of IM to experience stimulation $(\beta=0.077, t=$ $1.151, P>0.05)$, external regulation $(\beta=0.059, \mathrm{t}=0.881$, $P>0.05)$ and introjected regulation $(\beta=-0.045, \mathrm{t}=-0.662$, $P>0.05)$ were not significant.

The effects of self-efficacy on amotivation $(\beta=-0.254$, $\mathrm{t}=-3.504, \quad P<0.001)$, external regulation $(\beta=-0.007, \mathrm{t}=-$ $0.009, P>0.05)$, introjected regulation $(\beta=0.042, \mathrm{t}=0.559$, $P<0.05)$, identified regulation $(\beta=0.342, \quad \mathrm{t}=4.861$, $P<0.0001)$, IM-know $(\beta=0.360, \mathrm{t}=5.144, P<0.0001)$, IMtoward accomplishments $(\beta=0.205, \mathrm{t}=2.792, P=0.01)$, and IM-to experience stimulation (0.093, $\mathrm{t}=1.250, P>0.05)$.

The regression analysis results demonstrated that there was statistically significant contribution of the variables to the variane of academic achievement. The total coefficient of determination $\left(R^{2}\right)$ was $0.323(F=$ $8.328, P<0.0001)$ that is $32.3 \%$ of the total variance in academic achievement was explained by the composite effects of self efficacy, identified regulations, amotivation, IM-to know, IM-toward accomplishments, IM- to experience stimulation, external, and introjected variables. Of which $9.79 \%\left(30.31 \%\right.$ of $\left.R^{2}\right)$, was contributed by selfeffficacy, $7.89 \%\left(24.43 \%\right.$ of $\left.\mathrm{R}^{2}\right)$, by identified regulation $6.65 \%\left(20.59 \%\right.$ of $\left.R^{2}\right)$ by amotivation, $3.29 \%(10.19 \%$ of $\left.R^{2}\right)$, by IM-to know, $3.16 \%\left(9.78 \%\right.$ of $\left.R^{2}\right)$, by IM-toward accomplishments, $0.71 \%\left(2.20 \%\right.$ of $\left.R^{2}\right)$, by IM-to experience stimulation, $0.68\left(2.11 \%\right.$ of $\left.R^{2}\right)$, by external regulation, and $0.15 \%\left(0.46 \%\right.$ of $\left.R^{2}\right)$ by introjected regulation.

The third purpose of the study was to compare mean score difference between male and female students on the variables observed. To do this independent t-test was employed and the results are indicated in Table 3 below.

As indicated in Table 3. Males scored higher means in PCO, ID-R, $(P<0.05)$ IM-K and AcaAchi, $P<0.0001)$. However, no significant differences were observed on the other variables. Furthermore, additional comparison made on the average performance of male and female students achievement mean scores on Mechanics and heat, General Chemistry, Preliminary Mathematics, General Biology and college English. The t-value revealed that male students scored higher means in Mechanics and Heat I, M (2.484), SD (0.813) $P<0.05$, General Chemistry 
Amare Sahile

Table 3: Sex difference in mean scores on academic performance, self-efficacy \& motivational orientations

\begin{tabular}{|c|c|c|c|c|c|c|}
\hline \multirow{2}{*}{ Variable } & \multicolumn{2}{|c|}{ Males $(n=99)$} & \multicolumn{2}{|c|}{ Female $(n=81)$} & \multirow{2}{*}{ t- Test } & \multirow{2}{*}{$P$-Value } \\
\hline & $\mathbf{M}$ & SD & $\mathbf{M}$ & SD & & \\
\hline SelfEff & 32.051 & 3.898 & 30.284 & 6.57 & -2.588 & $<0.05$ \\
\hline AMO & 6.091 & 2.313 & 6.321 & 2.649 & 0.622 & $>0.05$ \\
\hline EX-R & 15.071 & 3.321 & 14.209 & 3.656 & -1.653 & $>0.05$ \\
\hline INT-R & 12.495 & 3.671 & 12.691 & 3.622 & 0.359 & $>0.05$ \\
\hline ID-R & 16.091 & 2.592 & 15.259 & 2.845 & -2.049 & $<0.05$ \\
\hline IM-K & 16.495 & 2.887 & 14.938 & 3.404 & -3.320 & $<0.001$ \\
\hline IM-A & 13.556 & 3.317 & 12.803 & 3.088 & -1.563 & $>0.05$ \\
\hline IM-S & 11.957 & 3.377 & 11.741 & 2.957 & 0.457 & $>0.05$ \\
\hline AcaAch & 12.434 & 2.643 & 9.383 & 3.604 & -6.546 & $<0.001$ \\
\hline
\end{tabular}

$\mathrm{M}$ (2.636), SD (0.725) $P=0.05$, College English, M (2.414), SD (0.670) $P<0.05$. But no gender differences were observed on Math and Biology ( $P>0.05)$. Moreover, the mean scores revealed that the most important forms of motivation for the students in this samples were, in decreasing order: identified regulation, IM- to know, external regulation, IM- toward accomplishments, introjected regulation, IM-to experience stimulation and amotivation.

\section{DISCUSSION}

The major objective of this study was to investigate whether self-efficacy, intrinsic, extrinsic and amotivation styles predict students' academic achievement. The second purpose was to examine gender differences on the variables compared and the third one was to examine whether there exist relationships between the variables compared.

As the results revealed, gender differences were clearly observed in the variables of perceived competence, intrinsic motivation to know, identified regulation and performance where males scored significantly higher means than females. However, there were no gender differences on external regulation, IMtoward accomplishments (although the means were in the predicted direction), IM- to experience stimulation, introjected regulation and amotivation. One could infer from the results that male students perception of competence probably helped them to display selfdetermined forms of motivational styles (i.e. IM-to know and identified regulation), which enabled them, exceed their female counterparts in performance. This result was contrary to the existing literature (Vallerand and Bissonnette, 1992; Blaise et al., 1990; Vallerand et al., 1993; Vallerand, Fortier and Guay, 1997) who reported that female students were more competent in their ability, intrinsically motivated, integrated and identified, but less externally regulated and amotivated toward academic activities than males. This difference could be attributed to cultural and due to traditional gender-role socialization practices; in our context males are more favored to be competent motivated and independent than females. Support for this.

Results obtained from correlational analysis indicated that gender, perceived competence, IM-to know, IMtoward accomplishments and identified regulation had strong association with performance $(P<0.01)$. This means that in both gender groups, students who scored high in these variables obtained higher scores in their performance than those students who exhibited low level of perception of competence and self-determined motivational styles. On the other hand, amotivation had
Sci. Technol. Arts Res. J., July-Sep 2014, 3(3): 176-184

significant negative relationship with performance $(r=-$ $0.268, P<0$. 001). This means that less students were amotivated the more was their performance. However, IM to experience stimulation, introjected regulation and external regulation were failed to correlate with performance. This result is exactly in agreement with the findings obtained by (Vallerand et al., 1992, 1993) who reported that ones perception of competence and selfdetermined motivational styles (e.g., IM to know, IM toward accomplishments and identified regulation have significant relationship with students self-reported grades. Interestingly, they stressed that IM to experience stimulation lack importance in education than a faulty measurement. On the other hand, Blaise et al., 1990, Pelletier et al., 1995 found out that IM to experience stimulation was an extremely important source of motivation in other life domains such as in the quality of couple relationship and sports. Moreover, non selfdetermined motivational orientations, external and introjected regulations and amotivation were not related to student grades (Vallerand et al., 1992 1993; Vallerand Fortier and Guay, 1997; Vallerand and Bissonnette, 1992). Grolnick and Ryan (1987) suggested that performing a learning task with a predominantly low selfdetermined regulatory style lead to poor conceptual learning.

Concerning the relationship between extrinsic motivation and outcomes, past research in the field has led one to assume that extrinsic motivation is generally negatively related to outcomes, the relationship between extrinsic motivation and outcomes depends on the type of extrinsic motivation involved (Deci and Ryan, 1991; Vallerand and Bissonnette, 1992). In the context of the present study, non self-determined types of extrinsic motivation, namely external and introjected regulation, were not related to achievement. However, selfdetermined type of extrinsic motivation (identification) found to relate to outcomes. Thus, this leads us to share the suggestion made by Vallerand and Bissonette (1992) Vallerand et al., (1992, 1993); Deci et al., (1991) that extrinsic motivation need not lead to negative effects. It can also be beneficial for the individual, depending on the type of extrinsic motivation involved we know little about the other types of extrinsic motivation and the effects they may have on achievement behavior.

In addition, separate correlational analyses were conducted for males and females. The results asserted that, in the case of males, perceived competence and the two extremes of motivational styles, IM- to know and amotivation correlated significantly in the positive and negative directions respectively with performance. But the case was not true for other variables. The correlation between the other variables and performance were not significant. This may indicate that males confidence in their ability probably enhanced them to achieve more for the reason they were intrinsically motivated to know, i.e. to learn more about the courses given, broaden their knowledge and discover new concepts and ideas which they never learned before. In the light of this, Harter and Connell (1989) were able to show that the most important determinant of intrinsic motivation toward school was efficacy affect.

Just as males, except self efficacy and amotivation, a different trend observed for females. In the case of females, identified regulation and IM toward accomplishments were strongly and positively related to 


\section{Amare Sahile}

academic achievement. But the relationships between the other variables were not significant. This may show that females' perception of self efficacy to academic activities helped them to achieve more for the possible reasons they were identified with and internally motivated to accomplish educational tasks. Moreover, their learning and subsequent achievement in the university were more informational or because meaningful to them in the sense that achieving better in university education eventually will enable them to enter the job market in a field they like than males who showed interest to know more about courses given and develop their knowledge.

Regarding the predicting effects of self-efficacy, intrinsic, extrinsic and amotivation forms of motivation on academic achievement, Beta coefficients displayed that self-efficacy, IM-to know, IM-toward accomplishments and identified regulation had strong positive effects. This means that when feelings of efficacy are enhanced selfdetermined intrinsic and extrinsic motivation styles increase students' achievement. On the other hand, amotivation had a negative significant effect on academic achievement. This means the more students are amotivated the less will be their academic achievement.

The direct effect of self-efficacy on academic achievement $(\beta=0.278, \mathrm{t}=4.245, \quad P<0.05)$, identified regulation $(\beta=0.252, \mathrm{t}=3.843 \quad P<0.0001)$, IM-to know ( $\beta=0.139, \mathrm{t}=2.014, P=0.05)$, IM-task accomplishments $(\beta=$ $0.155 \mathrm{t}=2.306, P<0.05$ were all positive. On the other hand, the direct effect of amotivation on performance was negative $(\beta=-248, t=-3.441, P<0.0001)$. Based on the present study self-efficacy, identified regulation, IM-to know, IM-task accomplishment and amotivation, were found to be predictors of academic achievement. This result is in consonant with the findings of Vallerand and Bissonnette (1992), Vallerand et al $(1992,1993)$ who reported that self determined forms of intrinsic and extrinsic motivational style, i.e. identified regulation, have a predicting effect on students academic achievement and can influence free persistent behavior in a field setting. Printich and De Groot (1990) reported that intrinsic value in learning among junior science students related to selfregulation and persistence.

On the other hand, the role of amotivation on achievement is also noteworthy. Amotivation was a very important predictor of students' performance in this study, being negatively related to achievement. The present findings support Deci et al. (1991) analysis of its effect on achievement and congruent with findings obtained on the relation between amotivation and outcomes. (Fortier Vallerand and Guay, 1995; Vallerand et al., 1992, 1993; Vallerand, Fortier and Guay 1997, Blaise et al., 1990) who reported that an amotivational event leads to a negative feedback, showing a person's lack of skill that reduces ones competence and intrinsic motivation and performance. The predicting effect of academic competence and self-efficacy on achievement was also stressed in local studies conducted on high school students (Amare, 2001; Yalew 1997). Tamire (1995, 1997) reported that students' self-confidence and interest in the subject were important perceived causes for academic success.

Promoting greater self-determination, that is more selfinitiation of behavior and greater personal responsibility, is an important developmental goal. In terms of education (Deci, et al., 1991 Deci and Ryan, 1991; Vallernd and
Sci. Technol. Arts Res. J., July-Sep 2014, 3(3): 176-184

Bissonette, 1992) suggested that it has become more apparent that motivational orientations in the forms of intrinsic motivation and extrinsic motivation, value internalization or purposefully engaging in an activity, lead to the type of outcomes that are beneficial to the individual and to the society. Through education a learner presumably acquires competencies and skills that make possible later economic and social adaptation. However, perhaps more significant than skills per se is the growth of motivation and interest in exercising, elaborating and applying them (Ryan Connell and Deci, 1985). Similarly, Grolnick and Ryan (1987) suggested that learning is a developmental process involving elaboration and integration of internal structures. As a process of development, the energy for learning begins from within and so requires active participation on the part of the learner.

\section{CONCLUSION}

In conclusion, it is believed that promoting self-efficacy and internalized motivational orientations should be given high priority in educational endeavors. Students need to understand the personal utility of learning and science achievement in building the nation. Valuing educational activities autonomously while doing course activities have enormous contribution. It is therefore, important to design intervention strategies with the aim of internalizing the value of education and achievement, for students encounter problems of social adaptations to the new environment which may create a passive set during their first year of learning in the university.

The results of this study therefore, underscore the importance self-efficacy and motivational orientations in science achievement setting at university context. Further research seems needed in order to further our knowledge on the interaction between student self-efficacy, motivational orientations and science achievement in the real life setting like university education.

\section{REFERENCES}

Amare Sahile (2001). Effects of Academic Competence, Selfdetermination and Motivation on School Performance in Tana Haiq Secondary School. The Ethiopian Journal of Education XXI (1): 165-193.

Ames, C. (1994) Competitive, cooperative and Individualistic Goal structures: A Cognitive motivational analysis. In: Ames, R.E. and Ames, C (Eds.) Research on Motivation in Education: Student motivation (Vol.1, pp 177-207) New York: Academic press Inc.

Bandura, A. (1977). Self-Efficacy: toward a unified theory of behavioral change. Psychological Review 84:191-215.

Blais, M.R., Sabourin.S., Boucher, C., Vallerand, R.J. (1990). Toward a motivational modelc of Couple Happiness. Journal of personality and Social Psychology 59(5): 10211031.

Cameron, J. and Pierce, D.W. (1994). Reinforcement Reward and Intrinsic motivation: meta- analyses. Review of Educational Research 64(3): 363-423.

Deci, E.L., and Ryan, R. (1985). Intrinsic motivation and Selfdetermination in human behavior, New York: Plenum.

Deci, E.L., and Ryan, R. (1991) A motivational approach to the self: Integration in personality. In R. Dienstbier (Ed.), Nebraska symposium on motivation; Vol.38. perspectives on motivation (pp. 237-288). Lincoln, NE: University of Nebraska press. 


\section{Amare Sahile}

Deci, E.L., and Ryan, R. (2000). The What and Why of goal Pursuits: human needs and the Self-determination of behavior. Psychological Inquiry 11: 227-268.

Deci, E.L., Vallerand, R. D., Pelletier, L. G., Ryan, R.M. (1991).Motivation and Education: The Self-Determination Perspective. Educational Psychologist 26 (3\&4): 325-346.

De Charms, R. (1984). Motivation Enhancement in Educational settings. In Ames, R.E. and Ames, C (Eds.) Research on Motivation in Education: Student motivation (Vol.1,. 275-308) New York: Academic press Inc.

Dweck, C. S. (1986). motivational process affecting learning. American Psychologist 41: 1040-1048.

Fortier, M. S., Vallerand, R. J., Guay, F. (1995). Academic motivation and school performance: Toward a structural model. Contemporary Educational psychology 20: 257274. Graham,S.(1994). Motivation in African Americans. Contemporary Educational Psychology 64(1): 55-117.

Gronlick, W.S. and Ryan, R.M. (1987). Authority support in education: creating the facilitating environment. In Hastings, $\mathrm{N}$ and Schwas, J. (Eds.) New Directions in Educational Psychology: 2. Behavior and Motivation in the classroom (pp. 213-231) London: The Falmer press.

Gottfried, A.E. (1985). Academic intrinsic motivation in elementary and junior high school students. Journal of Educational Psychology 77: 631-645.

Harter S (1981) A new self report scale on intrinsic verses extrinsic orientation in the classroom: Motivational and informational components. Developmental Psychology $17: 300-312$

Harter S., and Connell,J.P. (1984).A model of children's achievement and related self-perceptions of competence, contronl and motivational orientation. In J.G. Nicholls (Ed.) The development of achievement motivation (Vol. 3, pp219-250). Greenwich, CT: JAI press.

Maehr, M.L. (1984). Meaning and Motivation: Toward a Theory of Personal Investment. In: Ames, R. and Ames, C. (Eds). Research on Motivation in Education: Student Motivation (vol.1, pp.115-144). Boston: Academic press inc.

Pelletier, L.G., Fortier, M.S., Vallerand, R.J., Tuson, K.M., Briere, N.M., Blais, M.R. (1995). Toward a New Measure of Intrinsic Motivation, Extrinsic Motivation, and Amotivation in sports: The sport motivation Scale (SMS). Journal of sport and Exercise Psychology 17: 35-53.

Pintrich, P.R., and De Groot, E.V. (1990). Motivation and selfregulated learning classroom academic performance. Journal of Educational Psychology 82(1): 33-40.

Reeve, J., and Deci E.L., (1996). Elements of the cognitive Situation that affect intrinsic motivation. Personality and Social Psychology Bulletin 22: 24-33.

Roedel, T.D. and Schraw, G. (1995). Beliefs about intelligence and Academic goals: Brief research report. Contemporary Educational Psychology 20(4):464-468.

Ryan, R.M. (1982). Control and information in the interpersonal sphere: An extension of cognitive evaluation theory. Journal of Personality and Social Psychology 43: 450-461.

Ryan, R.M. and Connell, J.P., (1989) perceived locus of causality and internalization: Examining reasons for acting in two domains. Journal of Personality and Social Psychology 5: 749-761.

Ryan, R.M., Connell, J.P. and Deci (1985). A motivational analysis of self-determination and self-regulation in education. . In Ames, R. and Ames, C. (Eds.), Research on Motivation in Education: Student Motivation: The classroom milieu (pp.13-51). New York: Academic press.
Sci. Technol. Arts Res. J., July-Sep 2014, 3(3): 176-184

Schraw, G., Horn, C., Christ, T.T., and Bruning, R. (1995). Academic Goal Orientation and Classroom Achievement. Contemporary Educational Psychology 20(3): 359-368.

Shunk, D.H. (1989). Self-Efficacy and Achievement Behaviors. Educational Psychology review 1(3):173-208.

Shunk, D.H. (1991). Self-Efficacy and Academic Motivation. Educational Psychologist 26 (3 and 4): 207-231.

Tamire Andualem (1995). Attributions of students to their Academic outcome in Addis Ababa University. Un published MA Thesis. Addis Ababa University.

Tamire Andualem (1997). Attributions and Academic Achievement of Education, Medicine and Polytechnic Freshman Students in Bahir Dar. The Ethiopian Journal of Education XVII(2): 63-78.

Thomas, J.W. (1988).Proficiency in academic Studying. Contemporary Educational Psychology 113(3): 265-275.

Tobias Sigmund (1994). Interest, Prior Knowledge, and Learning. Review of Educational Research 64(1):37-54

Urdent, T.C. and Mahear, M.L. (1995). Beyond a two goal theory of motivation and achievement: a case for social goals. Review of Educational Research 65(3):213-243.

Vallerand, Robert J. (1983). The effects differencial amounts of positive verbal feedback on the intrinsic motivation of male hockey players. Journal of Sport Psychology 5: 100107.

Vallerand, R.J. and Reid, G. (1984). On the Causal Effects of Perceived Competence on Intrinsic Motivation: A test of Cognitive Evaluation Theory. Journal of Sport Psychology 6: 94-102.

Vallerand, R.J. and Reid, G. (1988). On the relative effects of positive and negative verbal feedback on males' and females' intrinsic motivation. Canadian Journal of Behavioral Science 20(3): 239-250.

Vallerand R.J. and Bissonnette, R. (1992). Intrinsic, Extrinsic, and Amotivation Styles as Predictors of Behavior. Journal of Personality 60(3): 559-620.

Vallerand R.J., Pelletier, L.G., Blais, M.R., Briere, N.M., Senecal, C. and Vallieres, E.F. (1992). The academic Motivation Scale: A Measure of Intrinsic, Extrinsic, and Amotivation in Education. Educational and Psychological Measurement 52: 1003-1017.

Vallerand R.J., Pelletier, L.G., Blais, M.R., Briere, N.M., Senecal, C. and Vallieres, E.F. (1993). On the Assessment of Intrinsic, Extrinsic, Amotivation in Education: Evidence on the Concurrent and Construct Validity of the Academic Motivation Scale. Educational and Psychological Measurement 53: 159-172.

Vallerand R. J. (1992-1993). Academic Motivation Scale (AMS-HS 28): High School Version. Educational and Psychological Measurement (52 and 53).

Vallerand, R.J., Fortier, M.S. and Guay, F. (1997). Selfdetermination and Persistence in a Real Life Setting: Toward a Motivational Model of High School Dropout. Journal of personality \& Social Psychology 72(5):1161-76.

Weiner, B. (1984). Principles for a theory of Student Motivation and Their Application within an attributional Framework. In: Ames, R. and Ames, C. (Eds.). Research on Motivation in Education: Student Motivation. Boston: Academic press inc. vol.1, pp. 15-38.

Yalew E. (1997). Self-Efficacy, Perceived Importance, Attitudes, and Achievement in Physics among Tana Haik Comprehensive Secondary School Male and Female Students: A Path Analysis. The Ethiopian Journal of Education 17(1): 29-49. 